\title{
LA VACA QUE NOS MIRA: VIDA PRECARIA Y FICCIÓN
}

\author{
Martín de Mauro Rucovsky \\ Universidad Nacional de Córdoba, CIFFyH, CONICET, Córdoba, Argentina \\ martinadriandemauro@gmail.com
}

RESUMEN / ABSTRACT

\begin{abstract}
A partir de dos textos recientes, Cuaderno de campo, un relato del argentino Carlos Ríos publicado en 2014, y De gados e homens, novela breve de la escritora brasilera Ana Paula Maia publicada en 2013, nos proponemos indagar la figura de la vaca y en particular el rostro animal al interior del universo simbólico del matadero. En estos textos, el matadero y la mirada de la vaca iluminan, entonces, una política de la vulnerabilidad corporal que interroga y complejiza la conceptualización de Judith Butler sobre Emmanuel Levinas, el rostro y la vida precaria, la cual conserva una jerarquía implícita en favor del viviente humano. En efecto, estas reescrituras sobre mataderos funcionan como saber biopolítico sobre la precariedad, esto es, aluden a una vulnerabilidad compartida o precariedad de los vivientes que se mide y constata sobre los flujos de afectos de ese entre-cuerpos vacuno y humano.
\end{abstract}

Palabras clave: reescrituras de los mataderos, Carlos Ríos, Ana Paula Maia, precariedad, Judith Butler, Emmanuel Levinas, rostro, animalidad, antropocentrismo, biopolítica.

\section{THE COW THAT GAZES AT US: PRECARIOUS LIFE AND FICTION}

Draw from two recent texts, Cuaderno de campo, a story of the Argentinian Carlos Rios published in 2014 and De gados e homens, a short novel of the Brazilian writer Ana Paula Maia published in 2013, we propose to explore the figure of the cow and in particular the animal face within the simbolic universe of the slaughterhouse. In these texts, the slaughterhouse and the bovine face shows a politics of corporeal vulnerability that inquire Judith Butler's analysis of Emmanuel Levinas, the face and precarious life, which sustain and implicit hierarchy for the living human. Therefore, these re-writings of slaughterhouses work as a knowledge of precarity, that is to say, they point to a share vulnerability or living precarity that proves the affective and sensitive dimmension that emerges in the between human and bovine bodies.

KEYWords: Re-Writing of slaughterhouses, Carlos Ríos, Ana Paula Maia, Precarity, Judith Butler, Emmanuel Levinas, Face, Animality, Anthropocentrism, Biopolitics. 
Y como Salomón pensaba:

el hombre se parece al ganado,

así como muere el ganado muere éste también

Karl Philipp Moritz - Anton Reiser

A la luz y la sombra del 9/11 y la escalada belicista consiguiente, Judith Butler construye una caja de herramientas a partir de una constatación fundamental: el hecho de que puedan hacernos daño y que otros puedan sufrir distintas agresiones supone una consecuencia para el entendimiento de la vida corporal. La exposición corporal y el contacto indeseado pueden significar la aniquilación misma de un cuerpo. Y esa verificación, la del riesgo insuperable de desaparición y la de la vulnerabilidad constitutiva de la existencia corporal, se volverá instancia de enunciación de una ética y una política. En el desplazamiento que va desde la pregunta por el cuerpo sexuado y los procesos de materialización -vinculo directo con la teoría queer y posfeminista de los años 80-90-al denominado "giro ético" de Butler-desde Precarious life en 2004, incluyendo Notes Toward a Performative Theory of Assembly en 2015 hasta el recientemente publicado Vulnerability in Resistance en 2016- la pregunta ética remite a la cuestión de la vida (Chambers y Terrel 92; Huffer 131). Ante la potencia que adquieren los procesos de precarización en nuestras sociedades neoliberales (Lorey 8), Butler pone en el centro de su reflexión una vida corporal que se reconoce atravesada por una red de interdependencia con otros cuerpos. Vulnerabilidad corporal y vida precaria marcan los ejes de un deslizamiento entre precarity y precariouness que remiten a una ontología corporal.

Así, en Precarious Life (2004), Butler explora una vía que luego retomará en Parting Ways. Jewishness and the Critique of Zionism (2012a) en torno al pensamiento de Emmanuel Levinas. Tal aproximación tiene como propósito trazar una ética judía de la no violencia y además problematizar una ética que permita hacerle justicia a la precariedad compartida. El vínculo ético surge, de acuerdo con Levinas, como consecuencia del sometimiento a la interpelación no querida del otro. Es el rostro del otro (de la alteridad), como figura que comunica lo humano -lo precario y vulnerable de la vida-, el que me cuestiona, el que me interpela, el que me habla ${ }^{1}$. El rostro del otro

La proximidad del rostro del otro me hace una demanda ética en una triple ligazón con la muerte: primero el mandato bíblico "No matarás" ("no pondrás en peligro la vida del 
configura una situación paradojal, a todas luces irresoluble: si el otro es el que comunica el sentido de esta precariedad, esto significa que me tienta con el asesinato (me vuelve potencial asesino) y a la vez el mandato ético-teológico me prohíbe ejecutarlo -"No matarás"-.

Asimismo, Levinas aporta a Butler algunos elementos para un análisis cultural que considera las representaciones públicas, mediáticas y dominantes de lo humano, el dolor y el sufrimiento desde la figura del rostro. Al respecto, Butler señala que quienes gozan de representación - por caso, donde un rostro sea visibilizado- tienen más probabilidades de ser humanizados y por ello ser considerados vivas vivibles, dignas de conservación y luto. No obstante, los medios funcionan deshumanizando un conjunto de personas, justamente, mediante un encuadre (frame) personificado y un retrato desfigurado del rostro. ¿Es el rostro humanizante per se? Si es humanizante en determinadas circunstancias, ¿cómo se produce esta humanización? ¿No hay también una deshumanización que se efectúa en y por medio del rostro? En efecto, si la personificación efectúa a veces su propia deshumanización, ¿cómo podemos darnos cuenta de la diferencia entre el rostro inhumano pero humanizante y la deshumanización que puede tener lugar por medio del rostro? Se trata de dos formas de poder normativo: una opera produciendo una identificación simbólica del rostro con lo inhumano y la otra funciona a través de una sustracción y eliminación radical, de modo tal que allí nunca hubo nada humano, nunca hubo una vida y, en consecuencia, no se cometió asesinato.

Butler recupera algunos aspectos de la figura del rostro levinasiano, la inefabilidad u opacidad del mensaje del rostro y la interpelación que el rostro del otro me produce en tanto su reconocimiento, el de un cuerpo necesariamente vulnerable, sea una condición para sostener la vida o hacerla vivible. No obstante, se aleja de Levinas en tanto éste conserva una radical asimetría ontológica que opone el sí mismo (yo) al rostro del otro (alteridad) que me interpela. Desde allí, Butler recurrirá a una vulnerabilidad constitutiva de la existencia en la cual los sujetos se hallan, desde el inicio, en una zona de adyacencia y de cierta reciprocidad ontológica (precariedad compartida). La exposición mutua obliga al sujeto, que se presupone necesariamente

otro"), en segundo lugar el deseo e impulso asesino en tensión constante con el temor de sufrir violencia o de infligirla ("Mátame") y en tercer lugar, esa forma en la que otro se vincula con el yo en los términos de una amenaza de substitución, de ocupar el lugar del yo y desplazarlo ("Te mato"). 
humano, a reconocerse en su relación con procesos de vida que exceden la forma humana (inorgánico, técnico y animal):

Lo humano y la vida nunca coinciden completamente, un término con el otro. La vida humana no representa la completitud de la vida, y la vida no puede definir la totalidad del humano -entonces, lo que sea que denominemos vida humana consiste, inevitablemente, en una negociación de esta tensión. Tal vez, lo humano es el nombre que le damos a esta intensa negociación (Butler, Precarity Talk 174). No podemos entender la vida humana sin comprender cómo se conecta con otras formas de vida, mediante las cuales se trazan distinciones y continuidades. Si vamos por una posición relacional, entonces deberíamos entender que lo humano no solo tiene una relación con lo animal -entendido como el otro- sino también está implicado en su propia animalidad (Butler, Dispossession 34-35).

La caja de herramienta butleriana pone en el centro de su reflexión un bios precario que, como ella misma reiteradamente aclara, no coincide con el rostro de lo humano o la humanización ${ }^{2}$, y esa no coincidencia, ese umbral de disparidad, es la ocasión misma de interpelación ética y política. Sin embargo, a pesar de las consideraciones que Butler ensaya alrededor del rostro y de la vida precaria que excede la forma humana, su aparato analítico mantiene una suerte de privilegio oculto o jerarquía implícita por el viviente humano:

Vida precaria no es un concepto antropocéntrico pero si afecta a los humanos de manera distinta. Nosotros deberíamos poder hablar de las formas en que las poblaciones humanas son afectadas por condiciones precarias, especialmente cuando estas son producidas por el sistema económico. Especialmente cuando algunos humanos son sistemáticamente cada vez más pobres, todo el tiempo, y otros humanos son más ricos, todo el tiempo (Butler, La resistencia política).

Si se nos pregunta qué constituyen las condiciones para una vida vivible, tenemos que poder responder sin postular un ideal uniforme o singular para esa vida. En mi apreciación, no es una cuestión de encontrar que es "lo

2 El rostro no es exclusivamente humano, pero sí constituye, según Levinas, una condición para la humanización. Asimismo, agrega Derrida sobre Levinas, "el carácter originario, paradigmático y prototípico de la ética es un espacio solo de hombres y son hombres por eso" (Derrida, El animal que luego estoy si(gui)endo 130). 
realmente humano" o que debería ser una "vida humana". Después de todo, afirmar que los humanos son animales también, no es aceptar la bestialización como una condición disminuida o degradada de lo humano, pero sí conlleva repensar la dimensión de lo orgánico e inorgánico en las interrelaciones dentro de la cual, cualquiera reconocible como humano puede emerger. En otros términos, el animal humano nos permite repensar las condiciones de sostenibilidad de una vida (livability).

Precisamente, porque "lo humano" mantiene una fuerte carga política, y por esas mismas razones, debemos repensar su pequeño lugar dentro de un conjunto de relaciones, de allí que podamos hablar de las condiciones por las cuales "lo humano" es reconocido de modo diferencial. Cuando digo que "nosotros" tenemos que pensar a través de esta categoría, quizás me vea persuadida por el engaño del discurso humanista, en vistas de mostrar que la categoría aun nos cautiva incluso cuando intentamos desvincularnos de su dominio (Butler, Notes toward 133-134).

En lo siguiente vamos a explorar e insistir en la pregunta por el bios precario, los procesos de vida y las redes de interdependencia que, en principio, exceden la concepción de lo político y del imaginario sensible que Butler propone, lo que es decir, un paisaje corporal humano demasiado humano. En ese contexto, al menos desde los 90, uno de los impulsos más persistentes que ha recorrido la cultura argentina y brasilera -y por generalidad en América Latina- es la interrogación sobre aquellos cuerpos que devienen superfluos (prescindibles), las técnicas del abandono, la desposesión radical y la precarización neoliberal. En estos materiales estéticos, el tema de la precariedad no solo se tematiza como un nuevo mapa sensible y afectivo -sinónimo de vulnerabilidad, inestabilidad y desprotección- sino también como procedimiento a explorar en distintos registros formales y estilísticos. Es por ello que para abordar este campo de indagaciones en torno al bíos precario no partiremos del análisis crítico de Butler, sino a partir de las indagaciones de la cultura, en particular, dos textos recientes, Cuaderno de campo, un relato del argentino Carlos Ríos publicado en 2014 y De gados e homens, la nouvelle de la escritora brasilera Ana Paula Maia publicada en 2013. En estos materiales literarios nos proponemos indagar la figura de la vaca, ese imaginario recurrente de la cultura latinoamericana, y el universo simbólico alrededor del matadero. Por su parte, las reescrituras de los mataderos de Maia y Ríos ponen en escena la cuestión animal y en particular la mirada de la vaca. Allí advertimos una 
pregunta inicial: ¿por qué miramos a los animales? Estos materiales trabajan la relación entre animalidad y rostro -y veremos en detalle las escenas del mirar a los ojos del rumiante- desde donde se movilizan interrogantes que leeremos como tensores del planteo de Butler y Levinas: “¿Puede leerse el "no matarás" en los ojos del animal?” (Derrida, El animal 129) ¿Cómo dar lugar a la mirada animal, al rostro vacuno? ¿Existen diferencias y jerarquías entre una y otra mirada?

La vaca, al igual que la tierra y el agua constituye una figura fundacional del imaginario latinoamericano. La figura del animal, la vaca, se constituye en punto clave de ese ordenamiento de territorios, poblaciones y cuerpos en los imaginarios civilizatorios y en la modernidad cultural. Conquista y dominio del Estado nación, la patria es domesticación del territorio y de los animales, vacas, márgenes fluviales y puertos ${ }^{3}$. Esa inmensidad de la tierra que define a la pampa y al sertón es también el escenario de las vacas. Imagen diáfana y mascota nacional, la vaca es el símbolo animal por excelencia, proveedor de carne, cuero, leche o motivo de inspiración poética, pictórica y literaria (Becerra 5). En la figura del rumiante se condensa un entramado de conexiones múltiples, es decir, no solo se concentran los valores nutritivos de la leche -alimento de la niñez y la infancia-, sino también historias de madres o de nodrizas, historias del dar de comer, del comer-con otros y del comerse al otro (Rodríguez 348-357). Así lo tematizan un conjunto de materiales estéticos que vuelven sobre la figura-constelación de la vaca, entre ellos, las canciones ¿Alguna vez te miró una vaca de frente? de Miguel Abuelo en 1968 o Guitarra Negra (Uruguay for export) del uruguayo Alfredo Zitarrosa en 1977, la serie fotográfica Carneada de Nicola Constantino en 2000, el texto El año del desierto de Pedro Mairal en 2005, la obra dramatúrgica El niño argentino de Mauricio Kartun en 2006, El matadero de Martin Kohan en 2009, Bajo este sol tremendo de Carlos Busqued también en 2009, El naturalista de Alberto Muñoz en 2010, el registro fenomenológico del francés Emmanuel Gras en el filme Bovines A Cows Life de 2011, Lumbre de Hernán Ronsino en 2013, el poemario De cemento de Pablo Castro publicado en 2015, ¿Alguna vez

\footnotetext{
Al respecto, conviene revisar la singularidad de la figura del río en el trabajo de Franca Maccioni (2016) Contemporáneos del mundo. Políticas de la imagen y del recomenzar en la obra de Joaquin O. Giannuzzi y otros poetas argentinos en particular cap. 6.2.1 "Recomenzar la lengua: una voz anfibia". Tesis doctoral en Letras, FFyH, UNC (MIMEO). Asimismo el trabajo de María Moreno (2014) Subrayados. Leer hasta que la muerte nos separe. Buenos Aires: Mar dulce. En particular apartado "Agua" p. 17-21.
} 
te miró una vaca de frente? de Iñaki Echeverría y Esteban Castroman en 2015 y tantos otros.

Cuaderno de campo y De gados e homens escenifican una nueva proximidad entre el cuerpo y la vida-muerte del animal que según detallaremos, se mide en el rostro del rumiante. ¿Y por qué la mirada? Porque "allí se lee una reciprocidad intraducible al lenguaje pero articulable en términos de afectos y sensibilidad" (Giorgi, Formas comunes 98) -¿o deberíamos decir es articulable con el planteo butleriano de una "vulnerabilidad compartida"?-. Esa nueva proximidad con el cuerpo a partir del rostro animal es la dimensión afectiva y sensible que surge en el entre-cuerpos humano y vacuno.

Hablamos de un chivo expiatorio, un mártir y un animal rumiante. La vaca es eso, una figura paradigmática que se produce al interior de la máquina de lectura que es el matarife, es decir, un territorio, zona expansiva o universo del matadero que pone el foco en el hacinamiento de carne, cuerpos, cadáveres. De esa aspiración restauradora, de ese espíritu que procura organizar y clasificar el orden sensible de los cuerpos -siempre mezclados y superpuestos-, están hechos los mataderos. Los textos de Maia y Ríos nos permiten pensar cómo esta topografía de cuerpos y de territorios se ve continuamente desplazada y desbordada. El matadero es un foco en continuo desborde en tanto configura una matriz que se encuentra expandida por todo el territorio. En otros términos, la muerte animal no permanece ni en el matarife ni en los cadáveres vacunos sino que se vuelve inasible y contagiosa. La muerte, en efecto, se expande por todo el tejido social. El matadero, en tanto máquina de lectura biopolítica, trata de una geografía fallada, una limitrofia (Derrida, El animal 45) de la muerte desplazada ${ }^{4}$.

El matadero, al igual que el campo de concentración o las guerras, comparten un mismo espíritu alegórico: "fabricar cadáveres" (Agamben, Homo sacer III 70). Tal es la insistencia de esa analogía que bien puede leerse en distintos materiales estéticos y filosóficos, desde el imprescindible Los orígenes del totalitarismo de Hannah Arendt, incluyendo Primavera de café de Joseph Roth, la película ganadora del Oscar Son of Saul del húngaro László Nemes

$4 \quad$ Así lo ejemplifica el más reciente episodio: un camión transportador de ganado vuelca sobre la ruta provincial 92 en proximidad a la ciudad santiagueña de Añatuya-Argentina y los vecinos deciden faenar los animales allí mismo en la ruta, esto es, escenifican y realizan en acto, el matadero. Véase http://www.infobae.com/2016/05/26/1814180-volco-un-camionque-transportaba-vacas-y-un-grupo-vecinos-las-faeno-la-ruta/ (consultado 24/8/16). 
o el análisis de Wolfgang Sofsky en La organización del terror. Esa forma de producción de alimentos se vincula directamente con la organización social de las fábricas, la producción en masa y la racionalización de la fuerza de trabajo: al menos desde 1850, los mataderos de Cincinnati y Chicago con sus cadenas y ganchos en movimiento, disponen el cuerpo animal de forma vertical. Como sabemos, esta línea de ensamblado inspiró a Henry Ford en su ya canonizado Highland Park en Dearborn (1913), el sistema de piezas móviles, cadena de montaje horizontal que dispone el cuerpo mecánico -del automóvil- en etapas y disecciones progresivas (Shukin 87).

Pero al mismo tiempo, en el matadero aparece otra cuestión referida no solo a la muerte animal sino a la violencia. Lo que se conjuga, como se sabe, en un determinado imaginario cultural alrededor del matadero. Aquí la violencia no es cifra de un enfrentamiento o antagonismo político (tradición que ubica las polaridades -civilización y barbarie, bestias y civilizados, genocidio y resistencia- bajo el mando de un poder soberano que decide la vida y muerte de los cuerpos). Estos materiales nos señalan otro tipo de violencia que es incorporada en lo cotidiano, en la normalidad del trabajo y los flujos del capital, es más, agrega Gonzalo Aguilar, "la verdadera violencia es negar que tenemos violencia en los trabajos considerados normales" (Nuevas formas 3). Sin posibilidad de redimir la violencia, alrededor del matarife podemos leer una economía de la violencia y del capital, esto es, no la posibilidad de superarla (y veremos cómo Cuaderno de campo ensaya una hipótesis al respecto) sino la modernidad técnica del capital, entonces, una administración regulada, maquínica, técnica e industrial de la violencia. Si el matadero supone una separación social de la violencia, una limitación de la violencia y la muerte animal a determinados territorios, límites y fronteras prefiguradas, es por ello que "no sabemos qué hacer con ella" (Aguilar, Nuevas formas 3) más que gestionarla, dosificarla y regularla.

Matadero y rostro vacuno gravitan en torno a la muerte de animales y la indistinción de cuerpos humanos-animales. En los matarifes toda ontología que distingue lo humano y lo animal es desarticulada a fuerza de muerte y violencia. Allí se escenifica una corporalidad difusa, precaria, vulnerable y frágil. El matadero ilumina, entonces, una política de la vulnerabilidad corporal que interroga y complejiza la conceptualización butleriana y sus escenarios sociales. Por eso, el cuerpo animal y el matadero funcionan como saber biopolítico sobre la precariedad. La mirada de la vaca es, en este sentido, una operación de lectura que ubica y desplaza a Judith Butler en el cono sur, en la pampa y el sertón a través de la figura del rostro. 


\title{
UNA CRIATURA SIEMPRE PÓSTUMA: NACIDA PARA MORIR
}

\author{
Quiero mirarte, mirarte y que me mires \\ Quiero hablarte, hablarte y que me mires \\ Quiero mirarte, mirarte y que me mires \\ El mató a un policía motorizado- "El fuego que hemos construido"
}

En Cuaderno de Campo, la escritura de Carlos Ríos (Santa Teresita, 1967) hace de la vaca y el matarife la ocasión para un desplazamiento: allí donde lo vacuno remitía a un espacio rural y por ello confirmaba un cierto orden de lo natural, aquí el rumiante funciona desarreglando formas de vida y órdenes jerárquicos. ¿Qué decir de una vaca? Se trata, pues, de la tecnovaca, "dispositivo metálico forrado en cuerpo" (Ríos, Cuaderno 51), figura intersticial, compuesta de agregados técnicos-orgánicos, rurales e industriales. La vaca es una criatura que comparte una inspiración maquínica industrial en un doble sentido: por un lado, se ha convertido en una forma de producción industrial, es decir, un producto biotecnológico más o menos sofisticado, sujeto a las innovaciones científicas y la agroindustria. El rumiante pampeano es biotecnología encarnada, herramienta e instrumento fabril. La vaca es un organismo biotecnológico que reproduce una cierta naturaleza animal, en cuya carne lo tecnológico y lo natural se han difuminado (Haraway 251). Por otro lado, es fuerza de trabajo no remunerada, se trata de animales que trabajan y producen alimentos, vestimentas y derivados para otro conjunto de animales humanos. Como ocurre en la industria láctea o en el matadero, se convierten en mercancías vivas superexplotadas (Hribal 120-121).

¿Y qué decir de los trabajadores humanos del matadero? Zamorano, el protagonista de Cuaderno de campo, también es un empleado en la cadena que transforma el cuerpo en carne. O también, Zamorano y las vacas son parte de una misma fuerza de trabajo, esto es, unos y otros forman parte de una misma lógica de explotación y acumulación del capital (Hribal 80).

La forma cuaderno que cabalga entre una micro ficción y un cuento breve hace de su narrativa una escritura sintética, abreviada o, por qué no, una escritura sumarísima. La composición del texto procede por acumulación de escenas. Valga la hipótesis especulativa, la narración de Carlos Ríos no procede solo por figuración o alegoría del universo simbólico del matadero, más bien son los ensacolados en convivencia con las tecnovacas quienes logran figurar lo precario como procedimiento. 
Los ensacolados son vidas precarias e inestables que permanecen en la periferia colindante del matadero, en este sentido, son figuraciones de lo animal y de la animalización de quienes se alimentan de residuos, vísceras y desechos. La vida ensacolada y por analogía los olayas -otra figura intersticial de Carlos Ríos en El artista sanitario de 2012- remite a la masa demográfica indefinida que se aglutina en esa cercanía intensa entre especies, sin alcanzar lo humano o más bien excediéndolo. Su actividad define su destino y su forma de vida, subsisten gracias a bolsas -sacolas - y restos de vísceras vacunas. Quien se ensacola, quien vive ensacolado, son aquellos que han perdido la forma humana, revés de la figura humanizante, socializada y frecuentemente redentora del "trabajador". Menos que humanos y en cercanía con lo animal, el ensacolado es una figura transversal que no termina de demarcar el contorno de la persona -en el sentido teatral y jurídico del término- y por ello no tiene rostro humano. Cuerpo económicamente superfluo e incompetente-el ensacolado es menos que un residuo poblacional-. El devenir ensacolado es antes que un ser humano, un viviente impropio. Formulada en 1871, esta figuración también puede leerse en El matadero de Esteban Echeverría, se trata de la "multitud de negras rebusconas (...) un enjambre de gaviotas y los perros (...) Porción de viejos achacosos (...) una comparsa de muchachos, de negras y mulatas achuradoras (...) enormes mastines" (Echeverría 12 y 18). El ensacolado, los olayas y la zoología de Echeverría ponen en escena ese rasgo distintivo de contagio, racialización, precariedad y excrecencia de la forma de lo humano.

Y así comienza Cuaderno de campo: "Sea Ud. bienvenido al matadero La Suerte 1892". Podríamos decir, el nombre del matadero registra, en tono irónico, el destino y el azar de los vivos o los muertos, ensacolados o precarios, vacas o trabajadores. Paisaje corporal donde los vivientes ${ }^{5}$, sean estos humanos, animales, vacunos o subhumanos, comparten un mismo rasgo afectivo, lo que es decir, la vulnerabilidad y la exposición corporal. La suerte nombra al frigorífico y por generalidad al matadero como motivo recurrente de nuestra cultura, que adquiere una singularidad con tonos y matices específicos. La verticalidad y el enclave social del frigorífico remiten

\footnotetext{
Agamben rastrea genealógicamente el término paisaje (topiographia o skenographia), en el que descubre un operador crítico (ser en état de paysage) que concierte tanto al mundo humano como al medio ambiente animal en un sentido esencial que elude toda definción o que es inapropiable (The Use of Bodies 88-91).
} 
a los mataderos que Francisco Salamone (1897-1959) construyera primero en Villa María (Córdoba) -"Matadero modelo" reza el cartel en el exfrigorífico municipal-y luego en la geografía disgregada de la Pampa, en particular, la provincia de Buenos Aires -Coronel Pringles, Balcarce, Carhué, Guaminí-.

La suerte construye un cerco sanitario o más bien una frontera social que pretende aislar la muerte vacuna de la vida humana, y lo animal de lo humano. El matadero cumple una función social: poner a distancia y aislar la vida eliminable, consumible y productiva de vacunos con respecto a los humanos (Giorgi, Formas comunes 129-160). De allí su riesgo constitutivo, la contaminación, confusión o mezcla de cuerpos y especies que habita en el matadero, así sea leído como territorio donde ocurre y se escenifica la barbarie, como en El Matadero de Esteban Echeverría o bien como un foco de insalubridad poblacional para el entendimiento biomédico y las distintas políticas sanitarias (Salessi 56). En cualquier caso, la distinción entre unas y otras vidas evita que la muerte animal se mezcle, contagie e irrumpa en la vida de la comunidad -y aquí podríamos arriesgar, se trata de una tecnología higiénica e inmunológica del matadero--. Sensación de purificación, despojo y limpieza que el matadero comparte en espíritu con la institución museo (Oliveira 320) o el cementerio mismo.

Como decíamos, el matadero se construye como máquina narrativa que gira alrededor de la violencia y la muerte, la disrupción de flujos, líquidos y especies, así leemos a propósito de El Matadero de Esteban Echeverria "la literatura argentina comienza con una violación" (Viñas 142). En Cuaderno de campo, se trama, se piensa, se configura una posibilidad redentora de la violencia -que es herencia y tradición literaria también: "los mataderos saldrán de su universo clandestino para hacer la revolución" (Ríos, Cuaderno 23). Es a partir de la figura de la vaca que una conspiración se teje con aires revolucionarios. El viejo Crisóstomo Maseca de 82 años, otrora evangelista devenido dueño y patrón del matarife, confabula una promesa emancipadora para proteger a los "animales consumibles", es decir, existe un horizonte revolucionario que puede detener el curso de la violencia heredada o antes bien anteponerle la fuerza salvífica de la violencia revolucionaria.

En este punto, cabe subrayar, el protagonista de Cuaderno de Campo. Euclides Zamorano de 47 años es un "hombre perdido" que recién ingresa al matarife. Su temporalidad está cargada de nostalgia, podríamos decir, una temporalidad habitada por espectros: la de su hija muerta o la de su lengua nativa (el runasimi, idioma andino de la familia del quichua). En este escenario, Zamorano se convierte en célula terrorista; su objetivo es impedir 
la matanza de animales nuevamente. Este se representa en sueños como el "Salvador Acústico de los animales":

Verse en el ojo de las vacas está mal. Es un acto pernicioso. Zamorano se da cuenta de su error. Nunca hay que mirarse en el ojo de una vaca. Si esto sucede, la vaca lleva al matadero tu alma. Te chupa la vida... $\mathrm{Al}$ anochecer, Zamorano siente que su cuerpo hace menos presión sobre el colchón de lana (Ríos, Cuaderno 57).

¿Qué descubre Zamorano en la mirada de la vaca? La muerte de su hija -"que sabe a luz entre tinieblas"- se vuelve inteligible a través de la muerte animal. Así es como muerte animal y muerte humana se vinculan a través de cristalitos que se forman en tejidos vacunos. Mirada abisal del animal que no se realiza en el rostro vacuno sino antes bien en la microscopia de su ojo, su tejido sensible, los cristales oculares del rumiante. En la mirada a través del tejido sensible del vacuno se descubre un nudo temporal que vincula la vida en camino a la muerte del animal y la temporalidad de la muerte humana -“el espíritu de su niña"-.

Ese momento se vuelve un lugar de reconocimiento de una muerte común en donde la muerte del vacuno se torna contagiosa: "la vaca lleva al matadero tu alma". Si el humano frente al rumiante se ve interpelado a sacrificarlo (tal como indica Levinas "te mato"), y vale recordar que éste es su valor capitalizable en la fabrica-matadero, Zamorano se descubre en la muerte de ese otro: "Entra el miedo igual que espuma en el oleaje. Hay cuchillos en alza. Es como si las vacas les hubieran pagado a los hombres para llevar a cabo un suicidio colectivo" (Ríos, Cuaderno 37).

La muerte, expansiva a la mirada, le chupa la vida a Zamorano puesto que esa mirada magnética de la vaca, que es un cuerpo en camino a la muerte, deviene su propia muerte: "En la matanza se abre un ojo de sentido que devora. No importa que un ojo sea incapaz de devorar. El ojo de la matanza devora" (Ríos, Cuaderno15). Lo que sucede en ese acto pernicioso del mirar es que el límite (limitrofia) entre cuerpos, sus figuras y líneas divisorias, son franqueadas. Al traspasar la frontera se figura un foco de conexión y entonces contagio corporal: "la sangre de Zamorano que se mezcla con la de los animales” (Ríos, Cuaderno 80). 


\section{BRASIL Y SUS MATADEROS}

Publicado en 2013, De gados e homens (traducido como De Ganados y de hombres) de la brasilera Ana Paula Maia (Nova Iguaçu, 1977) nos coloca ante el sertón (sertâo) brasileño y en su interior, el matadero "Touro do Milo". Narrada con un estilo preciso, dentro de un registro descarnado y realista, $D e$ gados e homens construye un clima sensitivo de la descomposición: "o cheiro da morte em todo lugar" (Maia 37). La crítica vincula a Paula Maia con la vasta tradición de literatura brasilera, en particular, Grande Sertão: Veredas de João Guimarães Rosa o con la escritura de Rubem Fonseca y Nelson Rodrigues. Más aún, De gados e homens se inserta, no sin cierta fricción, en la larga estirpe de materiales contemporáneos sobre mataderos, animales y vacas: entre ellos, Humana festa de Regina Redha en 2008, el texto anterior de Maia Entre Rinhas de Cachorros e Porcos Abatidos en 2009, la crónica A revolução começa na carne de Marcio Renato dos Santos en 2011, la performance Sem título de Berna Reale en 2011, la instalación Monologo para um cachorro morto y $O$ de Nuno Ramos en 2008 o también la serie fotográfica Ocultos de Hugo Fagundes en 2016. A su vez, De gados e homens se inscribe, en términos más amplios, en los efectos de una insistencia cultural brasilera de largo aliento, como sabemos, la persistencia del motivo de la matanza y devoración del otro como rito: desde los sacrificios antropófagos anteriores y coetáneos a la época del descubrimiento, los movimientos vanguardistas, Macunaíma de Mário de Andrade y las teorías antropofágicas de Oswald de Andrade, la tropicália de los años sesenta, entre tantos otros (Schwartz 13-51). Esta es una línea que Maia mapea desde el complejo industrial posfordista la cual sitúa al matadero alrededor de la cadena alimentaria y su lógica del "hay que comer" - o deberíamos agregar "hay que matar y entonces devorar"-.

Maia trabaja sobre nudos de condensación de sentidos que gravitan alrededor del matadero. Se trata de pensar y narrar la gestión política del medio ambiente y de cómo afecta directamente la vida y la supervivencia de los cuerpos. Aquí la violencia se liga ya no a un enfrentamiento político fundacional (como en E. Echeverría) o a su salida redentora (promesa revolucionaria de Maseca en Cuaderno de Campo); antes bien se trata de un tipo de violencia incorporada a la lógica misma del trabajo y asociada directamente a procesos de precarización ambiental y ecológica. Lo que importa es que la relación entre los seres vivos (entre aquellos que se dicen hombres y los animales) es una relación de interdependencia con el medio en que viven. Hay, en este sentido, un modo de afecto con el ambiente y sus 
componentes que permite rastrear, a partir de la geografía corporal que dibuja el matadero "Touro do Milo", una zona de interdependencia corporal entre cuerpos, territorio, medio ambiente y recursos tecno-naturales. Si el matadero construye una frontera -siempre inestable- entre vida y muerte animal, en el relato de Maia son la sangre y las vísceras animales las que se expanden por todo el territorio hasta contaminar los ríos próximos al matarife:

É nesse rio que todos os matadouros da região lançam as toneladas de litros de sangue e resíduos de vísceras de gado (...) Chama-se Rio das Moscas, e, desde que os matadouros cresceram na região conhecida como Vale dos Ruminantes, suas águas limpas encheramse de sangue. No fundo desse rio está depositado todo tipo de coisa, orgânica e inorgânica. Humana e animal (Maia 29 y 99).

Asimismo el "Rio das Moscas" resume la historia de los líquidos y licores corporales, de la leche a la sangre, o del alimento al veneno, o podríamos decir, toda esta cadena de referencias alrededor de la vaca y el afluente acuoso remite, de algún modo, a la eucaristía cristiana y la pasión de Cristo (Rodríguez 348-357).

Alrededor del matadero "Touro do Milo" se matan vacas, operarios del frigorífico, gente en la ruta, y es así como De gados e homens construye un paisaje corporal y un particular clima social cargado de muerte y asesinatos: "A morte tange todo o perímetro percorrido, tanto na estrada quanto no rio contaminado que corta a região" (Maia 33).

De Milo proviene el toro o la misma Venus de Milo, referencia solapada de una herencia helénica clásica -isla perteneciente al archipiélago de las Cícladas en mar Egeo-. Aquí no es la exaltación de la armonía humana de Venus (Afrodita), sus proporciones dóricas, su potencia erótica y femenina, antes bien se trata del Toro de Milos o de la potencia industrial del cuerpo animal. En ambos casos, Venus y Toro de Milo comparten elementos que son centrales al imaginario cultural: sus cuerpos escenifican la reproducción de la especie o rituales de fertilidad, Venus por vía del deseo, Toro por vía de la reproducción vacuna. Patrona de las meretrices, prostitutas y cortesanas, el cuerpo escultural de Venus se encuentra mutilado, lo que marca, salvando las distancias de culto, el destino del cuerpo vacuno y su eventual disección cárnica.

En el centro de ese paisaje, la escritura de Ana Paula Maia tematiza una nueva proximidad con el cuerpo y la vida muerte del animal, en donde muerte animal y muerte humana resultan, finalmente, indistintas. A ello 
apunta Edgar Wilson, el aturdidor de vacas, quien defiende la vida así como defiende también un procedimiento detallado, una coreografía precisa, un modo de morir sensible y humanizado:

$\mathrm{O}$ boi caminha até bem perto dele. Edgar olha nos olhos do animal e acaricia a sua fronte. $\mathrm{O}$ boi bate uma das patas, abana o rabo e bufa. Edgar cicia e o animal abranda seus movimentos. Há algo nesse cicio que deixa o gado sonolento, intimamente ligado a Edgar Wilson, e dessa forma estabelecem confiança mútua (Maia 19-20).

Como dispositivo social y mecanismo narrativo, el matadero pretende ocultar, aislar y poner a distancia el sufrimiento y la muerte animal de la vida humana, la vida a proteger y hacer vivir, de las vidas desechables, desprotegidas, abandonadas (Giorgi, Formas comunes 130). La muerte animal que se dispone en las líneas de ensamblaje y se pretende ocultar del contacto humano delimita toda una política de la mirada, del consumo visual y del espectáculo. En principio, el animal es producido no solo como carne comestible sino también consumible en términos de espectáculo. En De gados e homens una suerte de estudiantes-turistas visitan el matadero y realizan un tour ${ }^{6}$ por el "anfiteatro" vacuno, la "galería" de aturdimiento y las líneas de disección:

Quando sai do banheiro, depara-se com o grupo de estudantes enfileirado (...) Alguns decidiram recuar quando avançavam para área de sangria, só em imaginar o que estariam prestes a ver. Estar diante de bois e vacas pendurados de cabeça para baixo pelas patas traseiras e com os pescoços cortados jorrando litros de sangue em tonéis fétidos, misturado a vômito e outros excrementos, não era o que eles tinham em mente. Ninguém sairá impune (Maia 211-212).

Justamente, allí se revela no solo el contraste entre lo que se ve y lo que se come -carne que llega a nuestras mesas todos los días-, sino también una imposibilidad para los visitantes turistas. De algún modo, el matadero

\footnotetext{
Vale recordar que desde 1860 , los tours de mataderos en la zona de Chicago Parkingtown se convirtieron en un divertimento popular que incluía una visita completa a las estaciones, cámara de lavado, enfriamiento, etc. (Shukin 87-104). En la actualidad, la visibilidad pública de los mataderos (registrar o difundir lo que sucede en su interior) en Estados Unidos está castigado por ley (Giorgi, Formas comunes 144).
} 
oculta y protege ese momento de contacto afectivo con la mirada vacuna y sus efectos expansivos. Ese modelo de clausura animal (semejante a las instituciones de encierro disciplinar: el cementerio, el manicomio, la cárcel, etcétera) se sostiene sobre una prohibición de contacto -vale la insistencia, visual y afectivo-.

Matadero y cuerpo vacuno gravitan en torno a la muerte de animales y la indistinción de cuerpos humanos-animales. De allí se explica el recurso a la conjunción "e", De gados e de homens (en su título original en portugués). Su protagonista, Edgar Wilson - cuyo nombre es homenaje solapado a Poe-, un hombre que trabaja en el matadero sacrificando vacas en su rol de aturdidor, se ubica en ese mismo punto de juntura ("e"), en donde el ganado deviene indistintamente humano y el hombre se descubre ganado. Y esto le ocurre a Wilson, en sintonía con Zamorano, a partir del tejido sensible de los cuerpos: "vibração do sangue em suas correntes sanguíneas, que às vezes se perde em sua consciência ao questionar quem é o homem e quem é o ruminante" (Maia 209).

En este punto de condensación del texto se hace foco no solo sobre la circulación de la mercancía, la demanda de una cuantía de cuerpos vacunos para su muerte y consumo, sino también sobre el reparto y distribución económica de la forma del morir, el marco religioso que dictamina una demanda específica y tipificada de consumo, o en otros términos, nos habla también de cómo producir esas muertes: curiosidad del relato, el sistema de faena judío -llamado corte kósher o Shojet-y el sistema de faena musulmán -llamado Halal o Haram- que producen una escena digna del campo de batalla entre vacas libanesas y vacas judías. Antagonismos económicos, religiosos y culturales que se animalizan, o deberíamos decir, se trasladan al corral vacuno. Ocurre que vacas libanesas y judías se mezclan por descuido, "As vacas israelenses gostam de pastar no território libanês" (Maia 152). Si las marcaciones y clasificaciones religiosas se dirimen en términos de corporalidad vacuna, entonces surge un problema de cuño epistemológico ¿Cómo leer esas diferencias religiosas en el cuerpo? ¿Cómo distinguir vacas enemigas entre sí?

Ana Paula Maia no se contenta con una detallada escritura sobre el funcionamiento del matadero bajo las coordenadas propias de la "nueva razón del mundo" neoliberal; su texto gravita alrededor de un suicidio colectivo de vacas y ese argumento es un foco central que anuda el relato. Maia introduce un evento extraño en el relato: el ganado, tan predecible y estandarizado en su comportamiento, decide acabar -de modo colectivo, lo que es decir, en 
manada- con su propia vida. Desde allí se ensaya una línea de agenciamiento animal (Hribal 143) en cuyo seno las vacas no son representadas como meras mercancías pasivas sino más bien con una cierta capacidad de resistencia -el suicidio colectivo- frente a un destino manifiesto. De gados e homens nos recuerda cómo la maquina antropocéntrica se sostiene sobre una producción alimenticia que se realiza como economía del asesinato animal, estructura sacrificial o como lógica del "hay que comer", esquema carno-falo-logocéntrico (en palabras de Derrida, Hay que comer 17). En términos que amplían el registro butleriano: la vida corporal humana se sostiene sobre un vínculo de interdependencia y exposición mutua, lo que también presupone la muerte e ingesta del otro, del animal, del viviente o bien su incorporación como alimento. Resuenan, en este sentido, las palabras del chef brasilero Alex Atala: "Detrás de cada plato hay muerte. Y la gente cierra sus ojos ante ella". Profecía de la tradición nacional latinoamericana: todas las vacas serán, tarde o temprano, carne a la parrilla. Y esto tiene una consecuencia decisiva: no hay salida posible a la industria cárnica de muerte sino acaso interrupciones o cortocircuitos temporales. Así, en De gados e homens las vacas se arrojan por un barranco y deciden, de algún modo, terminar con su vida ${ }^{7}$. El suicidio vacuno, que bien nos remite a lo lo insinuado en Cuaderno de Campo: "Es como si las vacas les hubieran pagado a los hombres para llevar a cabo un suicidio colectivo" (Ríos, Cuaderno 37), y en especial El matadero de Rodolfo Walsh (de 1967), en De gados e homens será la figura que demarca esta línea de fuga y agenciamiento animal, esto es, una intermitencia fugaz en la cadena (pos)fordista del alimento.

Edgar Wilson, exminero y sobreviviente, es el encargado de aturdir a los animales en el umbral próximo a su procesamiento industrial. El transcurrir de Wilson se parece al de Zamorano, personaje cabizbajo y tosco, marcado

7 Lo que nos reenvía a otra línea de tensión sobre el análisis butleriano: ¿podemos guardar luto por un animal no humano? ¿Es posible velar por una vaca muerta, acaso suicidada? ¿Por qué las vidas animales no deberían contar como vidas dignas de luto? ¿Es la muerte animal una muerte sin duelo? ¿Acaso las muertes de animales o los cadáveres vacunos califican como vidas? La posibilidad del duelo animal se lee en torno a la definición misma del espacio de lo común, la comunidad como comunidad de cuerpos y por tanto, en relación con una vida eliminable que no necesita de las fórmulas previstas de los rituales jurídicos, funerarios o religiosos. Una muerte sin comunidad, en la medida en que, como mencionamos, la vida animal es insacrificable, no produce condolencia, memorialización, etc. 
por una cadencia melancólica. Tal es la relación que Edgar Wilson mantiene con las vacas y sus colegas en el matadero Touro do Milo:

Enquanto segue viagem, Edgar Wilson mantém seu pensamento fixo na escuridão dos olhos dos ruminantes, esforçando-se para desenhar um leve traço que o intente a desvendá-los. Nem todo o esforço da sua imaginação é capaz de lançar luz nas trevas; nem naquelas produzidas por olhos insondáveis, nem na própria treva que encobre a sua maldade (Maia 41-42).

Los ojos y la mirada de la vaca, en esta escena, no permiten leer rostro alguno o semblante (Derrida, El animal 127-141), tal como señalara Levinas. Los ojos de las vacas están cubiertos de neblina y oscuridad, asegura el aturdidor. A diferencia de Zamorano, la vaca le es opaca a Wilson, éste no se ve reflejado en sus ojos. En ningún caso se trata de una incapacidad cognitiva o del orden de la patología biomédica (prosopagnosia o agnosia visual) ${ }^{8}$. El aturdidor es incapaz de revelar la mirada bovina porque ésta es una mirada tan profunda y abismal que resulta indescifrable:

Os olhos de um ruminante assemelham-se à noite. Dentro deles existe apenas escuridão, e ela não pode ser perpetrada. É constantemente insondável (Maia 99).

La subjetividad animal que se revela en la mirada de Zamorano y Wilson es simplemente intraducible. Y esto ocurre no solo porque carece de rostro o semblante en términos levinasianos sino porque también su cuerpo en camino a la muerte (del cuerpo a la carne o del cuerpo al cadáver) se halla en adyacencia al humano. Constatación de una vulnerabilidad compartida, el mundo en el que vivimos es mirado por otros seres, lo que establece un reparto jerárquico de lo visible (¿es la mirada humana centro de lo visible? ¿Es la mirada humana otro engranaje de la máquina antropocéntrica o de la jerarquía ocular-antropo-centrista?). El acto de mirar vacas permite rastrear una zona de entre-cuerpos que es, además un saber biopolítico de lo precario,

8 La prosopagnosia es una forma específica de agnosia visual definida por el médico germano Joachim Bodamer como la "interrupción selectiva de la percepción de rostros, tanto del propio como del de los demás, los que pueden ser vistos pero no reconocidos como los que son propios de determinada persona" (así lo informa Wikipedia, consultado $6 / 6 / 16)$. 
una física corporal de la interdependencia (somos vidas precarias). Así, Wilson descubre en la vaca y su mirada una instancia de reconocimiento de un espacio común, zona de transversalidad, entre cuerpos vulnerables o entre vivientes. Y, efectivamente algo pasa en la mirada de Wilson y Zamorano, algo que se expande y hace presión. La vaca, ese cuerpo en tránsito indefectible hacia la muerte -o deberíamos decir a la parilla-, se vuelve demasiada cercana y entonces ilumina una condición compartida que Gabriel Giorgi (2016) denomina, respecto a la cohabitación de humanos con perros, precariedad animal.

\title{
REMATADAS EN CORTAS PEZUÑAS
}

\author{
Pero \\ si la vaca y el chico se encuentran en un claro, \\ descalzos, \\ ¿se miran? \\ ¿o cada cual a lo suyo? \\ Gabriel Yeannoteguy - Pampa Playa Afuera
}

El tema de la mirada animal no se vincula a la primacía del ojo como régimen de visibilidad hegemónico o dispositivo visual en occidente -el denominado ocularcentrismo (Jay 13)-. Esto es, la cuestión del atisbo humano-animal no se reduce a la visualidad óptica de la mirada. Antes bien, la mirada entre humanos y vacunos trae a escena una reciprocidad intraducible que se lee en términos de una "atmosfera afectiva" (Ben Anderson 1). Esto es, un saber biopolítico sobre el viviente o una fuerza de saber que pasa por lo precario y la vibración afectiva de los cuerpos.

La densidad y profundidad de la mirada vacuna atraviesa estos textos y dispone elementos para pensar no solo la subjetividad y la vida animal sino también concepciones no antropocéntricas del sujeto (Giorgi, Formas Comunes 98). Cuaderno de campo y De gados e homens, uno y otro, de maneras disímiles, aluden a una vulnerabilidad compartida o precariedad de los vivientes que se mide y constata sobre los flujos de afectos de ese entre-cuerpos vacuno y humano (o física corporal de los afectos). Aquí nos encontramos ante la fragilidad del cuerpo vibrátil -esa otra forma de lo viviente vibrando en el cuerpo de uno-, que se plantea en la transversalidad de los cuerpos, en una actuación de cuerpos vulnerables, en relación y en 
contacto con el medio, con las cosas, con otros cuerpos atravesados (eso que llamamos vida precaria, en el sentido más expansivo del término).

De algún modo, Cuaderno de campo y De gados e homens responden a la siguiente pregunta: “¿Puede leerse el "no matarás” en los ojos del animal?" (Derrida, El animal 129). O, mejor, postulan las siguientes preguntas: ¿Cómo dar lugar a la mirada animal, al rostro vacuno?, ¿existen diferencias entre una mirada y otra? En efecto, ambos registros y personajes permanecen fieles a un mismo esquema: tanto Zamorano como Wilson descubren en la mirada una instancia de reconocimiento de una muerte común

Era a imagem dele que estava diante de si, refletida nos olhos da vaca, pouco antes de morrer. A imagem da besta. Diariamente é a si que enxerga quando mata, pois aprendeu a ver sob a neblina que encobre os olhos do animal (Maia 188).

La matanza es un caldo en el que todos, sin excepción, nos cocinamos (Ríos, Cuaderno16).

Lo que se establece en esta zona de adyacencia común, entre cuerpos vulnerables, entre vivientes es el reconocimiento de la vida a través de la muerte, o en otros términos, de una muerte sin duelo o rito funerario (condición sine qua non de una vida vivible en términos butlerianos):

Edgar sente-se tão afinado com os ruminantes, com seus olhares insondáveis e a vibração do sangue em suas correntes sanguíneas, que às vezes se perde em sua consciência ao questionar quem é o homem e quem é o ruminante (Maia 209-210).

¿Cómo será la muerte? ¿Un borbotón de agua en el ojo de la vaca que deja todo así, blanco sobre blanco? La sangre de la sangre de Zamorano que se mezcla con la de los animales (Ríos, Cuaderno 80).

A partir de una zona expansiva e inestable, el límite abisal entre hombre y animal es reconsiderado y desplazado, en la intermitencia del "verse en el ojo de las vacas". Mirada vacuna que ilustra, en este sentido, una condición compartida en términos de afecto y sensibilidad.

Entonces, ¿Por qué miramos a los animales? (Berger 1). Debemos subrayar, la mirada de la vaca es justamente ese cuerpo -o deberíamos decir, esa carneentre la vida y la muerte que no es el otro del hombre, su revés radical y su alteridad infinita. Más bien, como De gados e homens y Cuaderno de campo advierten, ese cuerpo vacuno, esa muerte sin duelo, se vuelve demasiado 
cercana. La mirada vacuna nos habla de una "atmosfera afectiva" en donde los cuerpos se expanden y se vuelven contagiosos. Y ese arrojarse más allá de la forma humana es lo que justamente no se resuelve en el mapa social trazado por Butler. Se trata de excedentes de cuerpos, afectos corporales y tejidos sensibles (los cristalitos que se forman en tejidos vacunos de Zamorano y la vibração do sangue em suas correntes sanguíneas de Wilson) que ponen en cuestión la asignación de humanidad. Excedente de cuerpos precarios que se hallan expuestos desde el inicio con otros procesos de vida.

\section{BIBLIOGRAFÍA}

Agamben, Giorgio. Homo sacer III. Lo que queda de Auschwitz. El archivo y el testigo. Madrid: Editora nacional, 2002. Lo abierto. El hombre y el animal. Buenos Aires: Adriana Hidalgo, 2006. The Use of Bodies. California: Stanford University Press, 2015.

Aguilar, Gonzalo. Nuevas formas de la violencia en el matadero de la literatura: sobre De ganados y de hombres de Ana Paula Maia. Texto de conferencia impartida en Conexões Itaú Cultural, en el marco del encuentro "O Olhar do Outro: a Recepção da literatura brasileira", 2015.

El que debe morir: matanza y sacrificio en la cultura brasileña de Gonçalves Dias a Hélio Oiticica. Texto de conferencia impartida en Yale University, Department of Spanish and Portuguese, 2009.

Anderson, Ben. Affective atmospheres. Emotion, Space and Society, 2(2), 2009 (77-81). Recuperado de: http://dx.doi.org/10.1016/j.emospa.2009.08.005. Revisado el 26 de julio de 2016.

Bailly, Jean-Christophe. El animal como pensamiento. Santiago: Metales pesados, 2014.

Becerra, Juan José. La vaca. Viaje a la pampa carnivora. Buenos Aires: Arty latino, 2007.

Berger, John. Mirar. Trad. Pilar Vázquez Álvarez. Buenos Aires: Ediciones de La Flor, 1999.

Butler, Judith. Precarious life. The power of mourning and violence. Londres: Verso, 2004. Press, 2012

Parting ways: Jewishness and the critique of Zionism. USA: Columbia University

“Precarity Talk" en TDR: The Drama Review 56:4 (T216) Winter 2012. New York University and the Massachusetts Institute of Technology

Dispossession: The performative in the Political. Conversations with Athena Athanasiou. USA: Polity press, 2013.

"La resistencia política como acto corporal" entrevista en Palabra de Mujer, 6 de Julio de 2015, Universidad de Costa Rica. Recuperado de: https://www.youtube.com/ watch?v=3i751-KIpHM. Revisado el 19 de julio de 2016. 
Notes toward a Performative Theory of Assembly. London: Harvard University Press. Versión castellana: Cuerpos aliados y lucha política. Hacia una teoría performativa de la asamblea. Trad. María José Viejo Pérez. Barcelona: Paidós, 2015.

Chambers, Samuel y Terrel Carver. Judith Butler \& Politics.Troubling Politics. New York and London: Routledge, 2008.

De Mauro Rucovsky, Martin. "El retorno del trabajo y la emergencia de lo precario". Dossier Crítica de la Economía Política. Nombres. Revista de Filosofia 30 (Diciembre 2016).

"Mirada de la vaca y precariedad animal". Bazar Americano julio-agosto 2016, Año XI, No 57, ISSN 2314-1646, Mar Del Plata. Recuperado de: http://www.bazaramericano. com/resenas.php?cod=625\&pdf=si. Revisado el 19 de julio de 2016.

Derrida, Jacques "Hay que comer" o el cálculo del sujeto". Confines 17, Versión castellana de Virginia Gallo y Noelia Billi. Revisada por Mónica Cragnolini. Buenos Aires, diciembre de 2005 .

El animal que luego estoy si(gui)endo. Madrid: Trotta, 2008.

Echeverría, Esteban. "El matadero". 1871. Prosa Literaria. Volumen XIII. Buenos Aires: Edit. Estrada, 1944.

Fillipi, Massimo y Marco Reggio. Corpi che non contano. Judith Butler e gli animali. Milano: Mimesis, 2015.

Giorgi, Gabriel. "Precariedad animal". Boca de sapo 21. Era digital, año XVII, Abril 2016. Recuperado de: http://www.bocadesapo.com.ar/pdf/giorgi.pdf. Revisado el 23 de junio de 2016.

Formas comunes. Animalidad, cultura, biopolítica. Buenos Aires: Eterna Cadencia, 2014.

Haraway, Donna. Ciencia, cyborgs y mujeres La reinvención de la naturaleza. Valencia: Cátedra, 1995.

Huffer, Lynne. "Foucault's Fossils: Life Itself and the Return to Nature in Feminst Philosophy". Foucault Studies 20 (December 2015): 1832-5203.

Hribal, Jason. Los animales son parte de la clase trabajadora y otros ensayos. Madrid: Ochodoscuatro ediciones, 2014.

Jay, Martin. Ojos abatidos. La denigración de la visión en el pensamiento francés del siglo XX. Madrid: Akal, 2007.

Levinas, Emmanuel. "Ética e infinito". El rostro. Madrid: La balsa de la medusa, 2000.

Lorey, Isabel. State of insegurity. Government of the precarious. Londres: Verso, 2015. Versión castellana: Estado de inseguridad. Gobernar la precariedad. Madrid: Traficante de sueños, 2016.

Maciel, María Esther. Literatura e animalidade. Rio de Janeiro: Civilizaçao Brasileira, 2016.

Maia, Ana Paula. De gados e homens. Rio de Janeiro: Record, 2013. 2015.

De ganados y de hombres. Trad. Cristian De Nápoli. Buenos Aires: Eterna cadencia,

Oliveira, Eduardo Jorge. Inventar uma pele para tudo. Texturas da animalidade na literatura e nas artes visuais (Uma incursão na obra de Nuno Ramos a partir de Georges Bataille). 
Tese Doutoral apresentada ao Programa de Pós- Graduação em Letras: Estudos Literários, da Faculdade de Letras da Universidade Federal de Minas Gerais, 2014 - UFMG (Mimeo).

Rodriguez, Federico. Cantos Cabríos. Jacques Derrida, un bestiario filosófico. Santiago: FCE, 2015.

Rios, Carlos. El artista sanitario. Córdoba: Postales Japonesas, 2012. Cuaderno de campo. Buenos Aires: Bajo la luna, 2014.

Salessi, Jorge. "El (primer) matadero". Médicos maleantes y maricas: higiene, criminología y homosexualidad en la construcción de la nación argentina (Buenos Aires: 1871-1914). Buenos Aires: Beatriz Viterbo, 1995.

Schwartz, Jorge. Fervor de las vanguardias. Arte y literatura en América Latina. Buenos Aires: Beatriz Viterbo, 2016.

Shukin, Nicole. Animal Capital. Rendering Life in Biopolitical Times. Minesota: Minesota University Press, 2009.

Viñas, David. Literatura argentina y realidad política. De Sarmiento a Cortázar. Buenos Aires: Edic. Siglo veinte, 1971.

Yelin, Julieta. La letra salvaje. Ensayos sobre literatura y animalidad. Rosario: Beatriz Viterbo, 2015. 